\title{
Melodrama, subjetividad y reconocimiento en la ficción televisiva. Una propuesta de abordaje
}

\author{
Melodrama, subjectivity and recognition in \\ television fiction. Proposal for an approach \\ María Victoria Bourdieu
}

Recibido: 11/09/2019

Aceptado: 15/01/2020

Publicado: 26/06/2020
María Victoria Bourdieu vbourdieu@campus.ungs.edu.ar https://orcid.org/0000-0002-7257-7461

Universidad Nacional de General Sarmiento (Argentina)

Resumen: Proponemos enunciar brevemente los conceptos que relacionan el melodrama con una forma de ser y estar en América Latina, el modo en que los medios de comunicación masiva, especialmente la televisión, lo han adoptado y adaptado, para constituirlo en "el modo" de narrarnos. Aportaremos una propuesta de aproximación a contenidos ficcionales televisivos que nos habilite a leer las apelaciones a subjetividades y reconocimientos particulares, siempre en tensión con otras ficciones de orígenes diversos, cuyas producciones cuentan con fuertes aportes de capital, talento y pericia. Esta invitación, en definitiva, no es otra cosa que una reflexión que intenta desentrañar la idea de que existe "una gran" aldea global de la que formamos parte indivisa, en oposición a la idea de que, pese a la gran penetración de producciones audiovisuales de diferentes latitudes, existen identificaciones territoriales que aportan a esa construcción colectiva de identidad latinoamericana, cuya mejor forma de entendimiento enraíza en lo melodramático. 
Palabras clave: Melodrama, Discursividad social, Ficción televisiva, Proximidad cultural, Reconocimiento.

Abstract: We propose to briefly state the concepts that relate the melodrama to a way of being and to be in Latin America, how mass media-especially television- have adopted it and adapted it to constitute it in "the way" of narrating ourselves. We will provide a way to approach to fictional content in television that allows us to read the subjectivities and particular recognitions, always in tension with other fictions of diverse origins, whose productions have strong contributions of capital, talent, and expertise. This invitation, in short, is nothing more than a reflection that attempts to unravel the idea that there is "a large" global village of which we are part of undividedly, as opposed to the idea that, despite the great penetration of audiovisual productions from different latitudes, there are territorial identifications that contribute to this collective construction of Latin American identity, whose best form of understanding is rooted in the melodramatic.

Key words: Melodrama, Social discursiveness, Television fiction, Cultural proximity, Recognition.

\section{Introducción}

En América Latina, el paso a la modernidad se ha dado de la mano de las tecnologías y formatos audiovisuales (Martín-Barbero, 1992, p. 14). El relato de la migración de las poblaciones rurales a las grandes ciudades tuvo su condensación a principios de siglo XX en la travesía de una joven provinciana que enfrenta la insondable y laberíntica vida ciudadana, no sin avatares que la lastiman, aunque la hagan más fuerte.

Este es el modo en que se eligió recrear las identidades latinoamericanas, no desprovisto de cierta moraleja que incluía la expectativa del ascenso social, sea por un esfuerzo desmedido, sea por la imprevista noticia de una identidad aristocrática inesperada, siempre plagada de una posibilidad azarosa que, difícilmente resulta una realidad para el gran número de espectadores.

Las propuestas audiovisuales que impregnaron (e impregnan) las pantallas 
televisivas, permiten articular narraciones sobre las maneras de ser y estar en esa Latinoamérica que se mete de lleno en los procesos de modernización, y el modo de decirlo que sigue eligiendo es, sin duda alguna, el melodrama, como articulador del modo de "representación" de unas prácticas de los sujetos insertos en un tipo de orden social, cultural y político de la actualidad de nuestras sociedades, construye una expresión cultural que permite comunicarnos e identificarnos, aunque de maneras siempre inacabadas.

Lo melodramático ha demostrado su enorme capacidad de dinamismo, de mutar adaptándose a nuevos desafíos que han puesto en tensión algunas de sus características de origen y, sin embargo, mantiene improntas constitutivas como las pasiones desbordadas, los excesos, la fatalidad que sólo la nobleza de sus héroes y heroínas puede revertir.

\section{El melodrama en Latinoamérica}

Para nuestra propuesta es necesario detenernos en la posibilidad de comprensión del melodrama como matriz cultural (Martín Barbero, 1998). Se trata de esa matriz de carácter narrativo que permite a sus públicos reconocer sus espacios, una forma de relatar el acontecer y las experiencias cotidianas (Salinas, 2014) que ha cristalizado en algunos géneros ficcionales. Las formas melodramáticas emergen en géneros, estilos, formatos y medios distintos, en épocas distintas, pero siempre conectando a los sujetos con sus experiencias e identidades en tanto lo melodramático supone la puesta en relato de experiencias cotidianas (Salinas, 2014). Si bien es cierto que Latinoamérica produjo y sostiene su mayor mercancía del mercado de la industria cultural en esta matriz (hablamos de la telenovela), el melodrama existe y puede encontrarse en otras muchas manifestaciones culturales y/o artísticas.

La aplicación de conceptos de conceptos teóricos de las ciencias sociales facilita el análisis y la comprensión del modo en que los textos melodramáticos construyen, a partir del campo afectivo, toda una contextualización histórico-cultural a partir de los medios masivos, aglutinando audiencias heterogéneas a partir de la apelación a las emociones, homogeneizándolas. Por esta y otras características de "lo melodramático" es que se lo considera mucho más que un género. Se trata de una estructura narrativa que supera ampliamente marcas convencionales, estereotipos o esencias temáticas, aunque esté constituida también por todo ello. 
Así, la narración del amor ${ }^{1}$ con gran aporte de pasión, emoción, drama e intriga que materializa el dolor en busca de la empatía y compasión de las audiencias, ${ }^{2}$ siempre se construye conectando a los sujetos con sus experiencias e identidades (Salinas, 2014) a partir del reconocimiento de contextos históricos situados, tal como lo plantean los estudios culturales de raigambre inglesa, que han sido adaptados, desplegados y potenciados a partir de aportes específicos de teóricos latinoamericanos. ${ }^{3}$ Se trata de una matriz cultural que interpela a los sujetos, proponiendo un reconocimiento y, en la misma operación, sugiere y construye las modalidades de vida en la modernidad, especialmente la urbana, la ciudad de los comunes, la ciudad "melodramática" que organiza la existencia (Salinas, 2014, p. 32).

El melodrama en Latinoamérica posee una larga tradición y ha contribuido especialmente a la conformación de naciones a mediados del siglo XIX (Sommer, 2004). En esa etapa se trataba de producir relatos unificadores (Salinas, 2014) en contextos de conformaciones identitarias heterogéneas de reciente (o incipiente) independencia del poder español. El relato pasional (que interpela emocional y afectivamente, que exacerba lo dramático y la intriga) operó como herramienta pedagógica para componer una narración que facilitó el reconocimiento, propició la construcción de una propuesta de sentido sobre cómo deberían "naturalizarse" los modos de vida en las nuevas naciones (p. 29). Esta característica (que adoptó el relato de nación en los países latinoamericanos) porta en sí una multifuncionalidad que ha sido definitoria en nuestras identidades. Se trata de una función formal, otra sentimental y una función política, inseparable al momento de constituir identidades ciudadanas.

El relato melodramático también fue desarrollado a principios del siglo XX para operar sobre la "nacionalización de las masas" que migraban a las ciudades, conforme lo presenta Martín-Barbero (1998). Este autor analiza esa especial transición entre dos formas de cultura diferentes: la "cultura popu-

1. Hablamos del amor entre una pareja (preferentemente heterosexual) cuya concreción se hace dificultosa por avatares sociales, económicos y/o políticos. El melodrama transita también los amores filiales, fraternales, nacionales, deportivos, entre otros.

2. Decimos "audiencias" en general, ya que planteamos que el público del melodrama puede estar constituido por espectadores, lectores, telespectadores, prosumidores, radioescuchas, entre otros.

3. Tales como Martín-Barbero, Grimson, Orozco Gómez, Vassallo de Lopes, Sánchez Ruiz y Bolaño, citados en este trabajo. 
lar", que arrastra en sí la carga de los excesos del melodrama y los relatos seriados de principios de siglo XIX, y la "cultura de masas" que absorbe esta tradición melodramática.

Si bien podemos rastrear los inicios del melodrama en la novela clásica decimonónica, es menester señalar que la matriz melodramática tiene hoy una vigencia como forma narrativa. Además, resulta imprescindible evitar la consideración de que lo melodramático puede manifestarse solamente en algunos géneros. En realidad, se trata de construcciones presentes en muchos discursos que se sostienen en diferentes materialidades y se transmiten por todos los canales de comunicación.

\section{Los medios masivos y la construcción de subjetividades}

En la actualidad ya no se discute el lugar relevante que ocupan los medios de comunicación en las estructuras de poder (Sánchez Ruiz, 2015). Los medios masivos han configurado un modo de presentar el mundo que, en la actualidad recrean, reproducen y adaptan las nuevas tecnologías. En el concierto internacional participan en los procesos económicos y políticos, construyendo sentidos de lo que definen como noticiable y/o decible. Para abarcar debidamente ese alcance es necesario reflexionar sobre algunas de las funciones que, históricamente han cumplido los medios masivos y su aporte a la consolidación o resistencia del poder -mediático, económico o político- (M. V. Bourdieu, 2016).

A partir de las construcciones mediáticas, las personas progresivamente han construido la imagen de sus vidas, los significados de sus prácticas y los valores que las sustentan. Las mediaciones en tanto formas en las que personas interactúan con los medios, reflejan un intercambio que se nutre de las identificaciones de sus audiencias, y en la misma operación, las constituye y recrea. Así, los medios proponen las conductas "socialmente aceptables" $\mathrm{y}$, por oposición, ejemplifican aquellas actitudes que deben considerarse una desviación socialmente desaprobada (M. V. Bourdieu, 2016). Como plantea Sánchez Roman (2014) los medios no sólo (in)forman sobre el mundo, sino que lo dotan de sentido (p. 68).

Autores de los primeros estudios culturales británicos, como Raymond Williams (1974, 1980, 1994, 2011), han avanzado en la tarea de presentar las 
prácticas culturales como "prácticas materiales", porque, como lo plantea Grimson (2018), "entre las principales variables que inciden en el funcionamiento de la economía y la política se encuentran las dimensiones culturales" (p. 8). Y esta afirmación invoca la necesidad de ahondar en la producción y el contenido culturales que aportan a las construcciones identitarias, que moldean, constituyen y fortalecen cada identificación (M. V. Bourdieu, 2016).

Pero, tal como han planteado Sánchez Ruiz (2015), Bolaño (2013) y Grimson (2018), no es la cultura la única perspectiva comunicacional que debe abordarse en el análisis de medios. El corpus mediático es, para estos autores, un campo de encrucijadas, multidimensional, cambiante y complejo. Esta especial característica define sus particularidades locales, regionales y/o globales. Se trata de un objeto de análisis dinámico, que cumple múltiples funciones en posible correspondencia y/o tensión con las realidades económicas, políticas y sociales en las que se construye. En esa multifuncionalidad de los medios, el proceso de acumulación de capital, por un lado, y la reproducción ideológica del sistema, por el otro, no pueden ser soslayados (M. V. Bourdieu, 2016).

Lo que afirmamos es que, en ese campo de encrucijadas, la obtención de beneficios económicos de las empresas mediáticas se da a partir de la preferencia de las audiencias. Entonces, ¿cómo las producciones mediáticas establecen conexiones con los grupos de audiencias?, ¿qué identificaciones o aspiraciones se articulan al momento de definir el "gusto" de las audiencias en un determinado momento y lugar? Ello en esa intersección fluctuante y nunca consolidada entre objetivos económicos, reproducción del sistema que habilita la propiedad de esos medios, e intereses políticos que actúan (no siempre de modo evidente) al apelar a alguna identificación (M. V. Bourdieu, 2016) y todas esas variables en relación con sus productos audiovisuales, sean o no "ficcionales", ya que, como propone Verón (1995),

lo que estoy tratando de afirmar es que el noticioso es tan ficcional como una "serie" o un programa de variedades. Tan "ficcional" o tan "real": no importa demasiado, porque el discurso de los medios está deconstruyendo, como se dice, la distinción misma. (p. 31)

El mencionado autor tiene algunas concepciones indispensables para pensar la construcción discursiva. Así, proponemos utilizar el estudio de los discur- 
sos sociales, entendidos como textos, es decir "conjuntos presentes en la sociedad que se componen de diversas materias significantes y abarcan una forma de abordarlos, que remite a aspectos extratextuales" (Verón, 1987, p. 17).

Recuperando la teoría de la discursividad o teoría de los discursos sociales de Verón (1987), entendemos que esta presenta una "dimensión translingüística" al formalizar dos problemas: materialidad del sentido y construcción de lo real en la red de la semiosis. Tal como este autor plantea, un discurso es una "configuración espacio-temporal de sentido". El análisis de ese sentido es el que nos permitirá comprender la conformación de las configuraciones sociales que esos discursos proponen.

\section{La construcción del otro}

Es importante reiterar que lo melodramático no es un género sino una estructura narrativa que puede leerse en diferentes géneros y discursos, está dotado de una cualidad que lo habilita a entrar y salir de diferentes géneros para construir algún tipo de representación audiovisual. Para ello se ha propuesto que el "melodrama" cuenta con una facultad transformacional, una capacidad que permite que sus estructuras puedan aparecer de modos distintos y bajo combinaciones diferentes. En función de esa especial característica Martín-Barbero (1992) afirma:

Lo que pone en juego el melodrama es precisamente el drama del reconocimiento ... En forma de tango o telenovela, de "cine mexicano" o de crónica roja, el melodrama trabaja una veta profunda del imaginario colectivo, y no hay acceso posible a la memoria histórica que no pase por el imaginario. (p. 28)

La gran versatilidad y poder de adaptación a géneros, formatos y productos mediáticos que tiene el melodrama como estructura narrativa, puede ejemplificarse en que el melodrama clásico incluye en su despliegue una moraleja que se desprende en general de fidelidades primordiales, de deberes morales socialmente adjudicados; en cambio el melodrama contemporáneo no necesariamente insertará estas premisas, quizás en razón de que han cambiado sustancialmente las bases de integración social en el transcurso de la historia del melodrama. 
Asimismo, en el melodrama clásico, "varias de sus piezas tienen características reaccionarias, como la aceptación del estado de las cosas, la estructura patriarcal del poder, el castigo del vicio, el triunfo de la virtud" (Salinas, 2014, p. 37) y, especialmente, la consolidación de los roles que la sociedad le otorga a cada sujeto/a conforme sus características de sexo, género, etnia y/o clase social.

Para lograr esas identificaciones, el melodrama propone la construcción de unos y otros, ya que, desde la infancia, los hombres y mujeres en formación incorporamos acabadamente las propuestas identificatorias que de nosotros realizan las producciones ficcionales. Para ello se hace imprescindible la construcción de un(a) y otro(a) de quien diferenciarnos.

Aquí se plantea como práctica representacional para la construcción del "otro" a la estereotipificación que funciona esencializando, reduciendo, naturalizando, haciendo oposiciones binarias respecto de "otros" imprescindibles a la hora de imponer una "pertenencia naturalizada" que ocluya la fragmentación y las individualidades. Esta práctica en particular pone en evidencia el poder de la representación. El estereotipo como practica significante ... reduce la gente a unas cuantas características simples, esenciales que son representadas como fijas por parte de la Naturaleza. (Hall, 2010, p. 429)

Entonces, la reducción y personificación de algunas pocas características (que se proponen colectivas) para conformar la ejemplificación de un "otro" representativo de todos los otros de su misma condición (económica, social, de género o etnia) es una herramienta utilizada en la estructura narrativa del melodrama y, en especial, en aquellas producciones que se proponen para públicos masivos.

Así, el melodrama clásico se conforma a partir de estereotipos que reúnen características relevantes de aquellos cuatro sentimientos a los que apela en su origen a través de la empatía vs rechazo, personificados en el héroe y el traidor (Martín-Barbero, 1992).

El traidor es quien deberá producir el "miedo", es la personificación de la maldad e inevitablemente amenazará a la víctima, quien llevará consigo toda la ternura y la comprensión del público, encarnando la "lástima" en su per- 
sona. Con el mandato impuesto, deberá el héroe asumir el rol de justiciero o protector; en tanto el "bobo" representa la presencia activa de lo cómico, la otra vertiente esencial de la matriz popular. Este personaje tiene su fundamental misión en relajar las tensiones en los momentos difíciles de la trama, además de consolidar la fortaleza de los vínculos, generalmente la amistad con el héroe (M. V. Bourdieu, 2008, p. 19).

Con estas herramientas, el melodrama ha construido históricamente caracterizaciones sociales de la pobreza, la delincuencia, la ambición, la autonomía sexual, las credenciales intelectuales, la belleza, las pertenencias de clase y "la dignidad", a partir de algunas pocas cualidades en sus personajes, exponentes de los cuatro sentimientos que movilizan la trama.

Pero también lo melodramático (en su devenir) ha incorporado una mirada crítica y subversiva con respecto de las estructuras de poder, que cuestionan el statu quo, sin aportar un final moralizante pleno de virtuosismo. Aquí también se demuestra la versatilidad de lo melodramático que, acorde con las modificaciones en las configuraciones sociales, incorpora cuestionamientos que llaman a la reflexión del espectador. En todo caso, de estas manifestaciones melodramáticas existen ejemplos que permiten indagar las configuraciones sociales que proponen construir, sostener o derribar las improntas de dominación, y sus aportes y pregnancia en otros medios de comunicación y en otros géneros discursivos.

\section{Televisión}

El interés por el abordaje del análisis de las distintas características de la televisión tiene un largo recorrido, aunque no siempre se lo consideró un objeto de estudio especialmente válido que aporte a la comprensión del todo social. La articulación entre la conformación de este medio y las diferentes configuraciones sociales recién fue abordada con suficiente especificidad transcurridas algunas décadas del inicio de las transmisiones televisivas.

Verón (2009, pp. 237-239), apartándose de las discusiones respecto de la "paleo" y la "neotelevisión" propuestas por Eco (1986), propone tres fases en la institución televisiva global: 
- La etapa inicial, desde la instalación de la televisión en el tejido social (años cincuentas a setentas), donde el contexto socio-institucional extra-televisivo proporcionó el interpretante fundamental, la idea de una ventana abierta al mundo exterior construido desde una localización nacional, donde el interpretante central es el Estado-nación. Coinciden aquí el colectivo comunicacional de los televidentes con el colectivo formal de los ciudadanos.

- En los ochentas, la televisión misma se convierte en institución-interpretante, fase que se extiende hasta fines del siglo XX. Se interioriza el espacio de los noticiarios, surgen los talk shows. Se produce una creciente visibilidad de las estrategias de enunciación. Aquí, plantea Verón (2009), la televisión "se desprende definitivamente del campo político" (pp. 238-239).

- En el tercer milenio sitúa el autor la tercera etapa de la historia de la televisión "de masas", donde se instala como interpretante "una configuración compleja de colectivos definidos como exteriores a la institución televisión y atribuidos al mundo individual, no mediatizado, del destinatario" (Verón, 2009, 239). Aquí, el mundo del destinatario irrumpe en la institución televisiva como representante del "afuera", ejemplificada por la explosión de los reality shows. Considera además que esta podría ser la última fase marcando el fin de la televisión "de masas".

A partir del desarrollo de las nuevas tecnologías, Scolari (2008) propone una cuarta etapa, la "hipertelevisión", signada por una experiencia de consumo "multipantalla", que fluctúa entre la navegación por Internet, los videojuegos, el trabajo multitarea en red y, recientemente, la incorporación de los teléfonos celulares como dispositivos de consumo de textos audiovisuales, entre otras funciones. Estas condiciones tecnológicas aportan a una convergencia mediática y cultural que no sería posible sin la interactividad y digitalización de la información.

\subsection{Ficción televisiva y melodrama}

A partir de esa particular construcción que articula los gustos populares con las producciones en medios masivos se están dando, en la actualidad, las interacciones con los nuevos medios de comunicación. Conocer y analizar 
las estructuras institucionales, las conformaciones económicas, las fusiones o disoluciones resulta una dimensión imprescindible, pero no la única (M. V. Bourdieu, 2016). También son definitorios los contextos regulatorios que facilitan o impiden procesos en pos de las altas concentraciones mediáticas. Todo ello contribuye a potenciar el poder económico de las instituciones mediáticas. Pero también es relevante comprender el modo en que aportan a la conformación, sostenimiento o mutación de una (esa) cultura, proponiendo conductas como funcionales o disfuncionales a la integración social, condicionando y/o adaptando contenidos útiles a sus propios intereses (M. V. Bourdieu, 2017).

Indagar y descubrir esas operaciones en las ficciones es, para el investigador, un especial desafío, ya que no son tan evidentes como pueden percibirse en otros géneros televisivos. Los personajes, las acciones que emprenden, su estética, las situaciones que enfrentan, están teñidas de un modo particular de ver el mundo, el de la propia institución mediática y los equipos que la componen. Por proponerse como prácticas individuales ocluyen (aunque no invisibilizan) la metonimia que establecen con lo colectivo. Entendemos que, bajo la lupa del análisis, estas producciones demuestran su posicionamiento respecto de identidades colectivas, tanto de grupos, etnias o nacionalidades, que marcan definitivamente una propuesta de conducta pública, ideológica y política que se concibe desde el poder o bloque de poder (M. V. Bourdieu, 2018).

En este punto, nos interesa recuperar algunas cuestiones centrales que permiten la consideración de la ficción televisiva como un objeto de estudio que facilita el abordaje de representaciones de identidades políticas, culturales y sociales. Vasallo de Lopes (2008) propone que la ficción televisiva porta una relación con las identidades colectivas y culturales contemporáneas. Por ello el conocimiento de esas articulaciones es clave para profundizar el análisis del modo en que las configuraciones sociales se redefinen y reinterpretan.

Para esta autora es la ficción televisiva, especialmente la seriada, el lugar donde emerge "la nación como lugar antropológico de identidades ... clave de interpretación de orientación de los procesos de identidad y culturales en curso" (p. 36). Estos productos aportan a la conformación de una comunidad emocional, "de actuar como conector de un 'nosotros' nacional" (p. 37). 
En la propuesta teórico-práctica de Straubhaar (1993), se establece una particular mirada respecto a la internacionalización de contenidos televisivos en América Latina, que surge de su lectura de la concepción de "desarrollo dependiente" de Cardoso \& Faletto (1978) que plantea las circunstancias de desigualdad y perjuicio para los países no desarrollados. Recupera algunos conceptos (aunque discute con estos) de la "teoría de la dependencia", que sostiene que la propagación del modelo comercial de los medios, la inversión extranjera en las empresas de medios (que en América Latina se dio en los inicios televisivos) y el poder de los publicistas multinacionales aportaron a la construcción de una hegemonía para lograr que los habitantes de los países del Tercer Mundo se sientan satisfechos con la porción que les toca (Straubhaar, 1993, p. 69).

Aunque su propuesta es mucho menos determinista, sí plantea cierto desequilibrio. También resume otra posición teórica, la que postula el "imperialismo de los medios", centrándose más en los desequilibrios de poder y en los flujos de los medios, pero reconociendo un gradiente de posibilidades, no sólo la dicotomía metrópoli-periferia (p. 71).

Para Straubhaar (1993), sin apartarse completamente de esas posiciones, los productores locales empezarían a competir con las producciones estadounidenses y europeas, y las audiencias tenderían a preferir su propia cultura, siempre y cuando dichos productos se encontraran disponibles. En definitiva, contrapone la "interdependencia asimétrica" (respecto de los desarrollos en la producción en las industrias culturales) con la "proximidad cultural", que facilita y cumple el deseo explícito de las audiencias que leen activamente la televisión para producir (a partir de ella) significados que están relacionados con su experiencia social (p. 72).

Para ejemplificar esta postura (que se propone como paradigma superador del desarrollo dependiente) recurre al caso de Brasil, afirmando que la preferencia de las audiencias ha sido ampliamente recogida por TV Globo (que cubre el horario principal con telenovelas, música y comedia) creando y emitiendo mayores cantidades de programación nacional, trasladando los contenidos "importados" a horarios de menor auditorio (p. 91).

No es casual, a nuestro juicio, que el ejemplo de Straubhaar (1993) sea la televisión brasileña. En ese país se dio el caso emblemático del desarrollo de una televisión privada en estrechísimo vínculo con el gobierno, en una alian- 
za ininterrumpida con la dictadura militar (1964-1984), de política autoritaria y apuesta al desarrollo económico nacional. La tendencia manifiesta a la gran concentración en este medio de comunicación se produjo mucho antes que en otros países latinoamericanos:

En una armónica reciprocidad, las telecomunicaciones desarrolladas por el Estado y la televisión privada, liderada por la familia Marinho, favorecen la integración de los dispersos mercados brasileños. (Druetta, 2011, p. 53)

Esta cuestión no es menor, ya que esa "armónica reciprocidad" no es otra que el apoyo mutuo entre las políticas de Estado (legislación, regulación y normativas) y el desarrollo de contenidos televisivos que, en Brasil, se fundaron con la impronta de sostener una "cultura nacional"; difícilmente transferible a otros países de la región. De todas maneras y más allá de la utilización de los ejemplos, la concepción de "interdependencia asimétrica" y "proximidad cultural" resulta de gran utilidad para el análisis y, en algún período particular, podrá ponerse en cuestión, aportando a una concepción que podría postularse como la cristalización de la "globalidad" de las prácticas culturales locales. Este es, sin duda, el desafío que nos proponen las propuestas ficcionales en plataformas streaming.

Ante estos desafíos globalizadores, se hace relevante la posibilidad de interpretación de propuestas identitarias en las ficciones televisivas locales, así como el concepto de ciudadano que construyen al caracterizar personajes y situaciones. La dimensión simbólica de la idea de nación y sus correspondientes pertenencias alientan a descubrir la propuesta política que, aunque opacada pero no indescifrable, nos invita a traducir (M. V. Bourdieu, 2018).

\section{2. ¿Agoniza la televisión abierta?}

Es importante señalar que existe cierto consenso en cuanto a la lenta, pero sostenida caída de la audiencia de TV abierta. En este sentido, Rivero (2017) afirma, para la Argentina, que la estrategia empresarial de los canales es minimizar y distribuir los riesgos, sosteniendo la tercerización en productoras independientes (iniciada en los noventas), mediante las co-producciones con socios locales o internacionales, y también mediante la compra de enlatados. 
Esta consideración tendría cierta coincidencia con el estallido de ficciones extranjeras en nuestras pantallas en prime time. ${ }^{4}$

En Argentina, algunos datos en relación a la pérdida de audiencia de la televisión abierta en los últimos doce años, hablan de un promedio de 13 puntos en razón de la migración a los servicios de streaming y on demand. También se menciona al cable como otra de las razones de la baja en el rating de los canales de televisión abierta (Marín, 2017). Aunque estas consideraciones plantean cierta oposición a lo sostenido por Mastrini et al. (2016) sobre el análisis de consumos de televisión, cuyos resultados demuestran que tanto por cable, por televisión digital, satélite o analógico, lo que mayoritariamente se consume es la televisión abierta (p. 82). Ese mismo análisis plantea que

la televisión sigue siendo el medio masivo de comunicación de mayor alcance social, y su consumo trasciende las fronteras sociodemográficas. Como se ha indicado, en Argentina la penetración de la TV por hogar se acerca al 100\% de los hogares, lo que da cuenta de la vigencia del medio a pesar de la proliferación de los medios emergentes sobre las redes digitales. (Mastrini et al., 2016, p. 81)

Sin embargo y dadas estas consideraciones, existe un análisis preliminar mediante el que se establece que las audiencias de ficción televisiva en pantalla abierta han disminuido considerablemente. Con relación al acceso a los servicios de streaming y on demand (OTT) de grandes grupos de audiencias (especialmente constituidas por los segmentos etarios de los "nativos digitales"), ${ }^{5}$ supone que eligen ver productos audiovisuales conectados a sus smartphones, computadoras, tabletas, televisores inteligentes, en los horarios y lugares que ellos deciden. Así, Internet se presentó como una enorme distribuidora de contenidos $24 \times 7$ en detrimento de la posesión en pocas manos de las plataformas de contenidos, y facilitando la fragmentación de las audiencias (Marín, 2017).

4. Recordemos que antes de 2014 también se emitieron "latas", especialmente telenovelas del más clásico estilo de países iberoamericanos que, en general, ocupaban las franjas de la tarde con niveles de audiencia moderados.

5. Esta categorización ha sido puesta en tela de juicio ya que: "se repite hasta el hartazgo que los niños que crecen rodeados de tecnología digital tienen una facilidad innata para usarla. Pero simplemente no existe evidencia alguna que sustente esta afirmación. De hecho, suponer que los niños son 'nativos digitales' muchas veces posterga la urgencia del alfabetismo digital" (Muro, 2017). 
Las pantallas de televisión seguirán atrayendo mediante su modalidad "en vivo" de eventos deportivos, algunos noticiosos (de una hora) compitiendo con canales dedicados exclusivamente a noticias que se ven por cable o TDA, también programas de entretenimiento (constituidos en plataformas informales de noticias y comentarios políticos) y, por supuesto, los reality shows, que siempre han respondido a las expectativas de sus productores.

\section{Una propuesta de abordaje de contenidos de ficción melodramática}

En este espacio, recuperamos la teoría de la discursividad social que propone Verón (1987), en una síntesis que favorece el abordaje de contenidos. Con este marco, nos parece imprescindible abocarnos al análisis de operaciones discursivas y el posible sentido que intentan circular. Nos proponemos entonces establecer aquella marcas y huellas que portan las producciones televisivas que aporten a la construcción de identificaciones culturales, sociales y políticas. Todo ello en vínculo irreductible con la "vida cotidiana" entendida como noción que abarca un conjunto de relaciones interpersonales (vida familiar, afectiva, barrial y laboral principalmente).

Proponemos, de la mano de Steimberg (1998, 2013), las tres dimensiones que facilitan el análisis de los productos mediáticos, que aportan a definir estilos y géneros, sin perder de vista que este abordaje constituye una herramienta analítica ya que, en el conjunto textual, operan como un todo (M. V. Bourdieu, 2009).

\subsection{Dimensión retórica}

Aquí recuperamos la propuesta de Steimberg (2013) respecto de que esta dimensión no implica la noción de adorno o decoración. Por el contrario, su análisis es imprescindible para abarcar el acto de significación del discurso: implica abordar todos los mecanismos utilizados, a partir de una combinatoria de rasgos del orden figural. Esto es aquellas operaciones metafóricas, metonímicas, la construcción arquetípica de personajes, sus formas de decir, su vestimenta, etc.

Es probablemente la dimensión que más nos acerque al concepto de "proximidad cultural" que planteamos anteriormente. También será necesario analizar 
los tipos de transformaciones que ocurren a lo largo del relato y qué funciones cumplen en relación a las otras dimensiones que proponemos analizar.

\subsection{Dimensión temática}

Conforme a Steimberg (2013), el tema (los temas) de un discurso son externos a este. Sólo a partir del conocimiento de la totalidad del texto es posible discernir a qué tema(s) refiere, ya que se trata en realidad de construcciones históricamente construidas que el discurso en análisis recupera una vez totalizado. No se trata entonces de una coincidencia en sus contenidos, sino de la comprensión de la centralidad temática a partir de la totalidad textual.

El análisis que proponemos también contribuirá a establecer si este tema principal permanece en la construcción de estas ficciones en particular. También habrá que indagar en los "motivos" inscritos en el texto que, más allá de las características del género, aporten a la ampliación y diversificación de contenidos de "actualidad" que permitan identificar aquellos indicios, guiños y huellas que aporten a la construcción de un presente sociopolítico (M. V. Bourdieu, 2009).

Es en esta dimensión y con la consigna expresada, que el investigador deberá abocarse a analizar el modo en que cada producto construye los verosímiles en el discurso de análisis. Todos los discursos y/o textos construyen un verosímil de género, como construcción cultural histórica que habilita a quien lo disfrute a definir la pertenencia de género: drama, comedia, tragedia, etc. En el caso de las ficciones televisivas, también encontramos características muy reconocibles por las audiencias.

La verosimilitud de género da lugar a motivos recurrentes, siendo reconocidos y aceptados: motivos que son reconocibles en el fragmento de un texto y aportan a la comprensión, tanto de su pertenencia genérica, como de las aristas temáticas propuestas. Los motivos en esta dimensión temática, son las suturas entre el tema y el texto, que aportan los indicios para descubrir el tema.

6. Siguiendo a Segre (1985), Steimberg (1998) propone que los motivos son reconocibles en un fragmento del texto, aunque pueden caracterizarse por una relación de exterioridad a este. En cambio, el tema siempre se define en función de los sentidos del texto en su globalidad (p. 48). 
Pero los textos también contienen otras señales que habilitan a otra verosimilitud, que tiene relación con los social: aquella correspondencia que nos invita a creer que una historia tiene (al menos tangencialmente) rasgos que la relacionan con una posibilidad de existencia de sus personajes, escenarios, acontecimientos, circunstancias que (a juicio de las audiencias) son factibles en la "vida real". Esto es, la adecuación del texto en análisis al verosímil social. También aquí podremos verificar la utilidad de esa "proximidad cultural" para ficciones locales.

Proponemos identificar los paralelismos y los contrapuntos de ambos verosímiles, teniendo en cuenta que es del verosímil social del cual esperamos ocuparnos en profundidad (M. V. Bourdieu, 2009).

\subsection{La enunciación}

La enunciación, última instancia de nuestros análisis de contenidos, refiere al efecto de sentido del texto (discurso o producto audiovisual) relacionado con los procesos de semiotización. Todo discurso se construye en una situación comunicacional que atiende a sus condiciones de producción y también a sus condiciones de recepción. En esta dimensión y a partir de los resultados del análisis de las características retóricas y temáticas del texto, se propondrá establecer las principales condiciones con que se construye el "enunciador" (que está muy lejos de ser el autor del texto o discurso) y también a quién o quiénes pretende dirigirse (aquel enunciatario ideal).

Ambos elementos (enunciador y enunciatario) son figuras útiles para la comprensión de la circulación de sentido de los textos, pero no debemos perder de vista que no se trata de personas ni de instituciones: se trata de constructos teóricos que habilitan a la debida comprensión del sentido de los productos comunicativos.

\section{A modo de conclusión}

Hemos propuesto aquí el abordaje de productos audiovisuales, considerándose especialmente aquellas matrices melodramáticas que han signado, de maneras más o menos evidentes, las construcciones de las subjetividades e 
identificaciones latinoamericanas. Al recuperar las concepciones de "interdependencia asimétrica" y "proximidad cultural" proponemos construir los parámetros mediante los cuales dicha proximidad pueda leerse incluso en producciones cuyo origen (o cuyo objetivo) no puede relacionarse con identificaciones locales.

Sin duda existe una interdependencia asimétrica referentes a producciones realizadas por industrias multimillonarias de enorme experiencia y desarrollo. Sin embargo, creemos que sigue siendo notoria la creatividad, originalidad y afectividad que las producciones regionales y territoriales aportan a la hora de construir reconocimiento y subjetividad. Empezando por la interpelación idiomática, los lenguajes cotidianos, la identificación de lugares, escenarios, colores y paisajes, proponen una "pulsión" que apela, sin ninguna duda, a emociones y sentimientos que escapan al mero goce intelectual de la calidad de guiones, actuaciones y factoría.

Aún ahora, en medio del desarrollo de una mundialización a la carta de contenidos audiovisuales, la apelación a un "nosotros" (a través de guiños y marcas reconocibles para los espectadores que se vuelven cómplices en su reconocimiento) tiene su arraigo en la construcción de una cultura con tintes melodramáticos en nuestros pueblos latinoamericanos.

\section{Fuentes consultadas}

Barthes, R. (1982). Introducción al análisis estructural de los relatos. En R. Barthes, A. Greimas, C. Bremond, J. Gritti, V. Morin, C. Metz, T. Todorov \& G. Genette, Análisis estructural del relato (pp. 9-43). Tiempo Contemporáneo. https://clea.edu.mx/biblioteca/Barthes\%20 Roland\%20-\%20Anlisis\%20Estructural\%20Del\%20Relato.pdf

Bolaño, C. (2011). Comunicación y lucha epistemológica. En L. Albornoz (Comp.), Poder, medios, cultura. Una mirada crítica desde la economía política de la comunicación. Paidós.

Bolaño, C. (2013). Industria cultural, información y capitalismo. Gedisa. 
Bolaño, C., Mastrini, G., \& Sierra, F. (Eds.) (2012). Political economy, communication and knowledge. Hampton Press.

Bourdieu, M. V. (2008). Pasión, heroísmo e identidades colectivas. Un recorrido por los últimos veinticinco años de telenovela argentina. Biblioteca Nacional y Universidad Nacional de General Sarmiento.

Bourdieu, M. V. (2009). La telenovela y su aporte a la reconstrucción de la memoria social. El caso de Montecristo (Telefe Contenidos - 2006) [Ponencia]. XIII Encuentro Latinoamericano de Facultades de Comunicación Social, Universidad de La Habana, Cuba.

Bourdieu, M. V. (2014). Convergencias entre estudios culturales y economía política de la comunicación y la cultura: una aproximación a partir de los aportes de Stuart Hall. En E. Restrepo (Coord.), Stuart Hall desde el sur. Legados y apropiaciones. CLACSO.

Bourdieu, M. V. (2016). Abordaje de contenidos mediáticos: articulación y aportes de distintas corrientes de pensamiento. Actas de Periodismo y Comunicación, 2(1). https://www.perio.unlp.edu.ar/ojs/index.php/ actas/article/download/4202/3426

Bourdieu, M. V. (2017). Para leer la "contingencia” latinoamericana: estudios culturales y economía política de la comunicación y la cultura. Intervenciones en Estudios Culturales, 3(4). http://portal.amelica.org/ ameli/jatsRepo/53/5312006/html/index.html

Bourdieu, M. V. (2018). La ficción televisiva como objeto de estudio. ALAIC. http://alaic2018.ucr.ac.cr/sites/default/files/2019-02/GI\%202\%20 -\%20ALAIC\%202018_0.pdf

Cardoso F., \& Faletto, E. (1978). Dependencia y desarrollo en América Latina. Siglo XXI Editores.

Druetta, S. (2011). La televisión que no se ve. Eduvim.

Eco, U. (1975). La estructura ausente. Lumen. 
Eco, U. (1986). La estrategia de la ilusión. Lumen.

Grimson, A. (2011). Los límites de la cultura. Crítica de las teorías de la identidad. Siglo XXI Editores.

Grimson, A. (2018). Descendientes. Página 12. https://www.pagina12.com. ar/91492-descendientes

Hall, S. (2010). Sin garantías. Trayectorias y problemáticas en estudios culturales. Universidad del Cauca.

Marín, R. (2017, Marzo 20). Rating: Por qué la televisión abierta se va quedando cada vez más sola. La Nación. https://www.lanacion.com. ar/espectaculos/television/la-television-abierta-frente-a-los-desafios-del-presente-nid1995353

Martín-Barbero, J., \& Muñoz, S. (1992). Televisión y melodrama. Tercer Mundo.

Martín-Barbero, J. (1992). Introducción. En S. Muñoz(Ed), Televisión y melodrama. Géneros y lecturas de la televisión en Colombia. Tercer Mundo. http://pdfhumanidades.com/sites/default/files/apuntes/25\%20 -\%20martin\%20barbero\%20Television\%20y\%20melodrama.pdf

Martín-Barbero, J. (1998). De los medios a las mediaciones. Comunicación, cultura y hegemonía. Gustavo Gili.

Mastrini, G., Becerra, M., Marino, M., Gadano, J., \& Bieda, T. (2016). Televisión Digital: políticas públicas, expansión y consumos. En S. Marino (Coord.), El audiovisual ampliado. Ediciones Universidad del Salvador.

Metz, C. (1991). L'enuntiation impersonnelle ou le site du film. Meridien Klinchsieck.

Muro, V. (2017, Agosto 1). ¿Nativos digitales o espejitos de colores? La Nación. https://www.lanacion.com.ar/tecnologia/nativos-digitales-o-espejitos-de-colores-nid2048692 
Orozco, G. (2001). Televisión, audiencias y educación. Norma.

Rivero, E. (2017). Crisis en la industria de la ficción televisiva: entre las "latas" y la retirada del Estado. https://proyectoecanet.wordpress. com/2017/04/26/crisis-en-la-industria-de-la-ficcion-televisiva-entre-las-latas-y-la-retirada-del-estado

Salinas, C. (2014). Melodramas. Identidades y modernidades en la cinematografía latinoamericana contemporánea 1990-2010 [Tesis doctoral, Facultad de Filosofía y Humanidades de Universidad de Chile]. Repositorio de la Universidad de Chile. http://repositorio.uchile.cl/handle/2250/117484

Sánchez Roman, M. (2014). Los estudios culturales en la contingencia para repensar a los medios de comunicación. En E. Restrepo (Coord.), Stuart Hall desde el sur: Legados y apropiaciones. CLACSO; ENVION.

Sánchez Ruiz, E. (2015, Diciembre 7-11). El pensamiento crítico latinoamericano sobre medios de comunicación, en el contexto de las ciencias sociales [Conferencia de cierre]. Encuentro Internacional ICOM-ULEPICC, La Habana, Cuba. https://www.academia. edu/23178816/El_pensamiento_cr\%C3\%ADtico_latinoamericano_ sobre_medios_de_comunicaci\%C3\%B3n_en_el_contexto_de_las_ ciencias_sociales_2017

Scolari, C. (2008). Hipermediaciones. Elementos para una teoría de la comunicación digital interactiva. Gedisa.

Segre, C. (1985). Principios de análisis del texto literario. Crítica.

Sommer, D. (2004). Ficciones fundacionales: las novelas nacionales de América Latina. Fondo de Cultura Económica.

Steimberg, O. (1994). Nuevos presentes, nuevos pasados de la telenovela. Revista Sociedad, 5, 85-92.

Steimberg, O. (1998). Semiótica de los medios masivos. Atuel. 
Steimberg, O. (2013). Semióticas. Las semióticas de los géneros, de los estilos, de la transposición. Eterna Cadencia.

Stiletano, M. (2016, Enero 25). Cómo Turquía se convirtió en el país de las mil y una novelas. La Nación. https://www.lanacion.com.ar/espectaculos/television/las-mil-y-una-novelas-nid1865012

Straubhaar, J. (1993). Más allá del imperialismo de los medios. Interdependencia asimétrica y proximidad cultural. Comunicación y Sociedad, 18-19, 67-107.

Todorov, T. (1975). Lo verosímil. Tiempo Contemporáneo.

Trzenko, N. (2016, Enero 25). Una fascinación difícil de explicar. La Nación. https://www.lanacion.com.ar/espectaculos/una-fascinacion-dificil-de-explicar-nid1865014

Vasallo de Lopes, M. (2008). Televisiones y narraciones: las identidades culturales en tiempos de globalización. Comunicar, 30(XV), 35-41. https://core.ac.uk/download/pdf/37462978.pdf

Verón, E. (1987). La semiosis social. Fragmentos de una teoría de la discursividad. Gedisa.

Verón, E. (1992). Interfaces. Sobre la democracia audiovisual avanzada. En J. Ferry et al., El nuevo espacio público (pp. 124-139). Gedisa.

Verón, E. (1995). Relato televisivo e imaginario social. En N. Mazziotti (Comp.), El espectáculo de la pasión. Las telenovelas latinoamericanas (pp. 29-41). Ediciones Colihue.

Verón, E. (2001, Enero 5). A propósito de Expedición Robinson. Ni realidad ni ficción. Clarín. https:/www.clarin.com/opinion/realidad-ficcion_0_SyC7OzteCtl.html

Verón, E. (2009). El fin de la historia de un mueble. En M. Carlon \& C. Scolari (Coords.), El fin de los medios masivos. El Comienzo del debate. La Crujía. 
Verón, E. (2013). La semiosis social: Vol. 2. Ideas, momentos, interpretantes. Paidós.

Williams, R. (1974). Los medios de comunicación social. Península.

Williams, R. (1980). Marxismo y literatura. Península.

Williams, R. (1994). Sociología de la cultura. Paidós.

Williams, R. (2011). Televisión. Tecnología y forma cultural. Paidós. 